\title{
Transferable resistance in multiresistant Gram-negative bacteria isolated from hemocultures in Slovakia
}

\author{
N Kulkova', L Michalikova², JS Brnova ${ }^{1,2^{*}}$, V Krcmery $^{1}$ \\ From 3rd International Conference on Prevention and Infection Control (ICPIC 2015) \\ Geneva, Switzerland. 16-19 June 2015
}

\section{Introduction}

Antimicrobial resistance can be transferred between bacteria, and their plasmid-encoded resistant genes can be next transferred to other pathogens.

\section{Objectives}

The aim of this study was to assess the character of transferable resistance in multiresistant clinical isolates of Gram-negative bacteria from blood cultures in Slovakia.

\section{Methods}

This multicentre study was performed in November 2011 - January 2013. Altogether, 269 isolates of GNB from positive blood cultures of septic patients from hospitals in Slovakia were analysed. Transferability of resistancedeterminants was assessed by phenotypic methods with conjugational experiments. Strains of rifampin-resistant Escherichia coli 3110, rifampin-resistant Proteus mirabilis P38, rifampin-resistant Pseudomonas aeruginosa 1008, and rifampin resistant Pseudomonas aeruginosa 1670 were used as recipient strains. Escherichia coli strain ATCC 25922 was used as a control strain.

\section{Results}

Laboratory analysis of transferable resistance was performed with 213 clinical isolates, excluding 14 isolates for selectable resistance of rifampicin and nalidixic acid. Transferable resistance was confirmed in 61 isolates $(28,6 \%)$, of which $18(29,5 \%)$ in Klebsiella pneumoniae, $5(8,2 \%)$ in Proteus mirabilis and in 7 (11,5\%) other species. Cefotaxime (36; 59\%), ceftazidime $(28 ; 45,9 \%)$ and aztreonam $(23 ; 37,7 \%)$ resistances were the most frequently transferred resistotypes. Transfer only the one determinant of resistance was observed in 26 isolates $(42,6 \%)$ and the multiple transfer in 35 isolates $(57,4 \%)$. The most frequent recipient of antibiotic resistance determinants was strain Escherichia coli 3110 with 52 transfers $(85,2 \%)$, followed Proteus mirabilis P38 (30 transfers; $49,2 \%$ ) and Pseudomonas aeruginosa (9 transfers; 14,8\%). Interspecies transfer among the resistant bacteria was observed in 18 isolates $(29,5 \%)$.

\section{Conclusion}

In this study, we described high proportion of transferable resistance among multiresistant clinical isolated of Gram-negative bacteria in Slovakia.

\section{Disclosure of interest}

None declared.

\section{Authors' details}

'Laboratory of Molecular Microbiology, St. Elisabeth University, Bratislava, Slovakia. ${ }^{2}$ Department of Laboratory Medicine, School of Health Sciences and Social Work, Trnava University, Trnava, Slovakia.

Published: 16 June 2015

doi:10.1186/2047-2994-4-S1-P127

Cite this article as: Kulkova et al:: Transferable resistance in multiresistant Gram-negative bacteria isolated from hemocultures in Slovakia. Antimicrobial Resistance and Infection Control 2015 4(Suppl 1):P127. 